\title{
Fluorescent Analysis of the Cell-Selective Alzheimer's Disease A $\beta$ Peptide Surface Membrane Binding: Influence of Membrane Components
}

\author{
Olga Simakova and Nelson J. Arispe \\ Department of Anatomy, Physiology and Genetics, and Institute for Molecular Medicine, Uniformed Services University School \\ of Medicine (USUHS), Bethesda, MD 20814, USA \\ Correspondence should be addressed to Nelson J. Arispe, narispe@usuhs.mil
}

Received 10 December 2010; Revised 10 February 2011; Accepted 22 March 2011

Academic Editor: Brian Austen

Copyright (C 2011 O. Simakova and N. J. Arispe. This is an open access article distributed under the Creative Commons Attribution License, which permits unrestricted use, distribution, and reproduction in any medium, provided the original work is properly cited.

\begin{abstract}
We performed a fluorescent analysis of the binding of $\mathrm{A} \beta$ to the surface membrane of different types of cells lines such as PC12, GT1-7, and ex vivo neurons. Analyses were performed on sorted cells with membrane bound A $\beta$ Competitive binding between A $\beta$ phosphatidyl serine- (PtdSer-) specific binder annexin V and an anti-PtdSer antibody provided compelling data confirming the involvement of PtdSer as one of the surface membrane signal molecules for $\mathrm{A} \beta$. We found that populations of cells that exhibited high surface membrane binding affinity for $\mathrm{A} \beta$ also show higher membrane cholesterol levels compared to cells that did not bind $\mathrm{A} \beta$. This direct relationship was upheld in cholesterol-enriched or cholesterol-depleted cell membranes. We conclude that the initial process for the cell-selective binding by $\mathrm{A} \beta$, to later conversion of elemental $\mathrm{A} \beta$ units into larger structures such as fibrils or to the potentially toxic ion channel aggregates, is highly influenced by the membrane content of PtdSer and cholesterol in the cell surface membrane.
\end{abstract}

\section{Introduction}

It has been hypothesized that the primary cause for the cellular damage and the degeneration in the Alzheimer's disease $(A D)$ brain is a toxic interaction between the amyloidogenic peptides amyloid beta peptides $(\mathrm{A} \beta)$ and nerve cells [1]. The cellular degeneration observed in the AD brain is characteristically selective to the neuronal circuits in the neocortex, hippocampus, and basal forebrain cholinergic system. Cell selectivity in the toxic $\mathrm{A} \beta$ attack is also observed in vitro within cells in cultures externally exposed to the peptide $\mathrm{A} \beta$, where not all cells are equally affected by $\mathrm{A} \beta$ and some cells are even found to be resistant. This selective attack of $\mathrm{A} \beta$ to cells in cultures may embody the selective attack observed in cells of specific regions of the $\mathrm{AD}$ brain. The peculiarities of these neurons that predispose them in general to the selective attack of $\mathrm{A} \beta$ are not well understood. However, as the first effective interaction of $\mathrm{A} \beta$ with cells occurs at the surface of the cell membrane [2], observation in cell culture experiments suggests that the particular affinity of $\mathrm{A} \beta$ for specific cells resides in the composition of the surface membrane. Our earlier findings on a variety of neuronal cell lines and ex vivo neurons, sorted on the basis of affinity to bind $\mathrm{A} \beta$ showed that permanent intracellular and surface membrane conditions endorsed the initial sensitivity and the association between $\mathrm{A} \beta$ and the cell membrane [3]. The most prominent of the surface membrane conditions that establish this association is related to the presence of phosphatidyl serine (PtdSer) on the outer face of the surface membrane. PtdSer cell surface exposure is known to serve as a recognition signal during apoptosis, both for cell removal in apoptosis [4-7] and as a docking site for some proteins [8-10]. Therefore, the correlation between the presence of PtdSer on the outer face of the surface membrane and $\mathrm{A} \beta$ binding to cells suggests the PtdSer is a possible docking site for $\mathrm{A} \beta$ and deserves further investigation. The physicochemical interaction of $\mathrm{A} \beta$ with nonprotein components of the plasma membrane, such as monosialoganglioside GM1 and cholesterol, and with lipid bilayers of various compositions, has also been a subject 
of intense investigation [11-15]. It has been shown that the ability of $A \beta$ to insert into the membrane is critically controlled by the ratio of cholesterol to phospholipids [16]). Altering this ratio, by lowering the concentration of cholesterol, results in $\mathrm{A} \beta$ staying on the membrane surface region.

Many reports have described the mechanism for $A \beta$ cytotoxicity as a series of separate processes including $A \beta$ cell selection and membrane binding [3], incorporation into membrane [16, 17], and membrane permeabilization [18]. In addition, it has been shown that binding alone is not sufficient for membrane permeabilization [3, 19]. With the application of flow-cytometry and cell-sorting procedures in this investigation, we performed a fluorescent analysis of the binding process of $A \beta$ to the surface membrane of different types of cells lines such as PC12, GT1-7, and ex vivo neurons. Competitive binding between $\mathrm{A} \beta$ and an anti-PtdSer antibody authenticates the selective binding of $\mathrm{A} \beta$ to surface membrane PtdSer and provided compelling data confirming the involvement of PtdSer as one of the surface membrane signal molecules for $A \beta$. We found that populations of cells that exhibited high $\mathrm{A} \beta$ binding affinities also show higher membrane cholesterol levels compared to cells that did not bind $\mathrm{A} \beta$. This binding correlation was confirmed in cholesterol-enriched or cholesterol-depleted cell membranes. We conclude that the mechanism for $\mathrm{A} \beta$ cytotoxicity involves first a cell-selective binding to the cell surface membrane. This initial process is determined by the level condition of membrane components of the cell surface membrane such as PtdSer and cholesterol. The conversion of elemental units of $A \beta$ into either larger fibrillar structures or into potentially toxic ion channel $A \beta$ aggregates that will induce membrane conductance changes requires the initial binding of $A \beta$ at the surface membrane.

\section{Materials and Methods}

2.1. Cell Cultures. The immortalized cell line PC12, derived from a transplantable rat pheochromocytoma (American Type Culture Collection, Manassas, VA), immortalized hypothalamic neurons GT1-7 (provided by Dr. R. Weiner, University of California at San Francisco), and ex vivo cultures of hippocampal neurons from newborn rat brains, were grown in ATCC recommended media and in neurobasal medium/B27 (GIBCO), respectively. The preparations of these ex vivo cultures have been previously described $[2,3]$.

2.2. Flow Cytometry Analysis, Cell Sorting. To study $\mathrm{A} \beta$ binding and surface membrane, PtdSer cells were incubated in either PBS with $0.3 \%$ BSA containing $5 \mu \mathrm{M}$ of freshly prepared A $\beta 42$-FAM (fluorescein isothiocyanate) as recommended by the manufacturer (AnaSpec) for $80 \mathrm{~min}$ or annexin $\mathrm{V}$ buffer with the fluorescence conjugated annexin V-PE (Phycoerythrin) (Annexin V-PE apoptosis detection Kit I-BD Bioscience) for $20 \mathrm{~min}$. The specification from the manufacturer states that A $\beta 42$-FAM has a purity of $>95 \%$ and we confirmed the monomeric state of $A \beta$ in the stock solutions by polyacrylamide gel analysis. After incubation cells were washed 3 times and analyzed by flow cytometry (EPICs XL-MCL Beckman Coulter). Unless specified in the text, the flow cytometric analysis was made immediately after the very short period of time of exposure to $A \beta$ and to relatively low concentration of $\mathrm{A} \beta$. Therefore, these conditions are sufficient for $\mathrm{A} \beta$ binding, but are not sufficient to induce a measurable externalization of PtdSer and apoptosis. Hence we consider that most detected PtdSer is prior PtdSer on the surface of the cell membrane. Cells with different $\mathrm{A} \beta$-FAM or annexin V-PE affinity were separated by a fluorescence-activated cell sorter (FacsAria, BD Biosciences), by low pressure (20 psi) and low speed (1000 events/s) [2]. To evaluate cell viability, parallel FACS tests were performed and the resulting scattergram analyzed. DAPI $\left(4^{\prime}, 6\right.$-diamidino-2phenylindole) was also used to fluorescently label cells for viability analysis in multicolor flow cytometry experiments. The purity of sorted cell groups routinely exceeded $80-90 \%$ [2]. The control cells were not treated with either Annexin VPE or A $\beta 42$-FAM but were still submitted to the same sorting conditions and pooled.

2.3. Changes in the Cell Surface Membrane PtdSer Levels. To decrease the levels of surface membrane PtdSer on PC12 cells, we screened the exposed PtdSer by using an antiphosphatidylserine monoclonal antibody (clone 1H6, Upstate). For control, we used the corresponding isotype antibody (Upstate). Based on preliminary experiments, the final antibody concentration in the culture media was $2 \mu \mathrm{g} / \mathrm{mL}$.

2.4. Changes in Membrane Cholesterol Levels. To decrease the surface membrane, cholesterol content, PC12 cells were cultured in the presence of $5 \mu \mathrm{M}$ mevastatin (Sigma) for 24 hours and/or treated with $1-16 \mathrm{mM}$ methyl- $\beta$-cyclodextrin (CD) (Sigma) for 40 minutes. When cells were cultured in the presence of mevastatin, Mevalonate $(500 \mu \mathrm{M})$ was simultaneously added to the culture medium to prevent cell growth inhibition. To enrich the cholesterol content of the membrane, cells were incubated with water-soluble $0.52 \mathrm{mM}$ cholesterol (polyoxyethanyl-cholesteryl sebacate; Sigma) for 2 hours.

2.5. Determination of Membrane Cholesterol Levels. To evaluate the membrane cholesterol content cells were incubated for 1 hour in PBS containing $400 \mu \mathrm{g} / \mathrm{mL}$ Filipin III (Sigma). Filipin is a polyene antibiotic frequently used as a probe for quantitative assessment of cholesterol content $[20,21]$. Cells were then $2 \mathrm{x}$ washed with filipin-free PBS and the membrane-bound filipin fluorescence was measured by Fluostar-Optima (BMG-Labtech). Cholesterol content of cells with different $A \beta$ binding affinity was analyzed immediately after washing off unbound $\mathrm{A} \beta$-FAM. Cells were incubated with $100 \mu \mathrm{g} / \mathrm{mL}$ of Filipin III for 40 minutes, $2 \mathrm{x}$ washed, and analyzed by flow cytometry (LSRII, BD Biosciences) for Filipin III (355 laser) and A $\beta$-FAM fluorescence (488 laser). 
2.6. Statistics. When applicable, data are presented as the mean of five experiments \pm SD. Origin scientific analysis software (OriginLab, Northhampton MA) was used to determine significant levels using student's $t$-test. The level of significance denoted with double asterisks means highly significant $P<.001$ values.

\section{Results}

3.1. A Remarkable Correlation Is Observed between $A \beta$ Binding Affinity and the Levels of Surface Phosphatidylserine in Different Types of Cells. We have previously observed that $\mathrm{PC} 12$ cells that exhibit $\mathrm{A} \beta$ binding affinity preferentially display measurable phosphatidylserine (PtdSer) in the surface membrane [3]. Here we perform a more detailed fluorescent analysis of this observation in various cell lines including ex vivo hippocampal neurons and GT1-7 cell line. Annexin V assay was used as a specific and standard overall accepted way for the detection of externalized PtdSer. We followed the $\mathrm{A} \beta$ and annexin $\mathrm{V}$ staining protocol previously described [3] and extended the analysis to different degrees of $\mathrm{A} \beta$ binding and to wider range of surface PtdSer levels. We first exposed cells to $A \beta$-FAM for a short period of time $(80 \mathrm{~min})$ and then to annexin V-PE. The results from the fluorescence analysis, based on levels of intensity of the cell-bound $A \beta$ FAM, showed three distinct subpopulations of cells within all three different types of cells. The fluorescence histograms shown in Figure 1 illustrate these distinct subpopulations for the case of PC12 cells. We have previously reported similar division of cells into subpopulations in ex vivo hippocampal neurons and GT1-7 cell line [3]. The cells were classified into a subpopulation of cells that did not bind A $\beta$-FAM (gated as subpopulation $\mathrm{A}$ ), a subpopulation of cells that show a high binding affinity for $\mathrm{A} \beta$-FAM (gated as subpopulation $B$ ), and a subpopulation of cells that show an extra high binding affinity for $\mathrm{A} \beta$-FAM (gated as subpopulation $\mathrm{C}$ ). The results from the fluorescence analysis, based on levels of intensity of the cell-bound annexin V-PE on each one of the subpopulations from the three types of cells, are shown in Figure 2. Cells which displayed surface PtdSer (annexin V-PE positive) are within the rectangles labeled $R$. A remarkable correlation was observed between the level of $A \beta$ FAM binding and the level of surface PtdSer. The table below shows representative results from the experiment shown in this figure in terms of the percentage of cells (\%) and the annexin V-PE Geometric-Mean of Fluorescence (GeoMF) in the gate $R$. Consistently in all three types of cells, a significantly higher percentage of cells in the subpopulations $\mathrm{B}$ and $\mathrm{C}$ (high and very high $\mathrm{A} \beta$-FAM binding) were detected as PtdSer positive. On the other hand, only a very small percentage of cells that did not bind $\mathrm{A} \beta$-FAM, subpopulation A, were detected as PtdSer positive. Similar results were consistently observed in three additional experiments. Notice that all PC12 and GT1-7 cells with extra high binding affinity for $\mathrm{A} \beta$-FAM (gated as subpopulation $\mathrm{C}$ ) are within the rectangles labeled $R$. Additionally, the annexin V-PE GeoMF for these cells presented values ten times higher compared to cells gated as subpopulation B.
3.2. A $\beta$-FAM Binding on Cells Sorted on the Basis of Annexin $V$-PE Binding. Sorted $P S^{+}$Cells Displayed the Highest Binding Affinity for $A \beta$-FAM. The correlation between $\mathrm{A} \beta$-FAM binding and surface PtdSer observed in the flow cytometric data shown in Figure 1 was also observed with fluorescenceactivated cell sorting. PC12 Cells were exposed to annexin $\mathrm{V}-\mathrm{PE}$, as described in Material and Methods. The annexin V-PE levels of fluorescence histograms shown in Figure 3(a) clearly group the cells into well-defined PtdSer negative $\left(\mathrm{PS}^{-}\right)$and PtdSer positive $\left(\mathrm{PS}^{+}\right)$cell groups. The rectangles in the figures specify the limits of fluorescence characterizing the groups. The numbers in the figure are the averaged percentage $\mathrm{PS}^{-}$and $\mathrm{PS}^{+}$cells from four experiments. This fluorescent analysis shows that almost one third of the cells $(32 \pm 3.5 \%)$ are $\mathrm{PS}^{+}$. This finding allows for fluorescenceactivated cell sorting based on annexin V-PE binding to separate subpopulations of cells with distinct binding characteristics.

We then examined sorted $\mathrm{PS}^{-}$and $\mathrm{PS}^{+}$groups of cells for $\mathrm{A} \beta$-FAM binding affinities. Sorted $\mathrm{PS}^{-}$and $\mathrm{PS}^{+}$groups and control PC12 cells were exposed to A $\beta$-FAM within 2 hours after sorting. The results from flow cytometric analysis of the sorted groups of cells exposed to $A \beta$-FAM are shown superimposed in Figure 3(b). The highest percentage of cells binding $\mathrm{A} \beta$-FAM $(88 \%, R 1$ gate, $\mathrm{A} \beta$-FAM positive cells) was found in the group of sorted $\mathrm{PS}^{+}$cells.

\subsection{Specific Antibody to PtdSer Reduces the Number of Surface} Membrane Binding Sites Available for A $\beta$-FAM Binding. To study the influence of the levels of PtdSer molecules on the surface of the membrane on the magnitude of $A \beta$-FAM binding to the cell surface, an antibody that specifically binds to PtdSer (anti-PS mAb) was used. PC12 cells were first treated with anti-PS monoclonal antibody and then exposed to annexin V-PE for PtdSer identification and to $\mathrm{A} \beta$-FAM to study $\mathrm{A} \beta$ binding. In previous experiments with artificial membranes and with cells in culture, we showed that $A \beta 42$-FAM behaves in the same way as native $A \beta$, since it forms ion channels and induces the same toxic effects on cells to the one induced by native $A \beta$. Furthermore, all these manifestation of $\mathrm{A} \beta 42-\mathrm{FAM}$ are prevented by the specific $A \beta$ channel blockers [22-24]. Therefore, we considered it safe and appropriate to use $A \beta 42$-FAM to study $\mathrm{A} \beta$ membrane binding. The $R 2$ gate, annexin $\mathrm{V}$ PE positive cells, in the multigraph Figure 4(a), shows that before the anti-PS antibody treatment, 38\% of cells were detected by annexin V-PE as $\mathrm{PS}^{+}$. When cells were pretreated with the anti-PS antibody, the percentage of $\mathrm{PS}^{+}$ cells detected by annexin V-PE was reduced to $22 \%$. This represents a $42 \%$ reduction in the number of detectable $\mathrm{PS}^{+}$cells. Our previous experiments suggest that both the anti-PS antibody and A $\beta$-FAM preferentially bind to PS $^{+}$ cells. Therefore, it will be expected that after a combined treatment the number of $\mathrm{PS}^{+}$cells detected by annexin VPE will be considerably more reduced. This is observed in the multigraph Figure $4(\mathrm{~b})$ that shows the number of $\mathrm{PS}^{+}$ cells after exposing cells to $A \beta$-FAM alone and to anti-PS antibody followed by A $\beta$-FAM. Although $38 \%$ of $\mathrm{PS}^{+}$for 


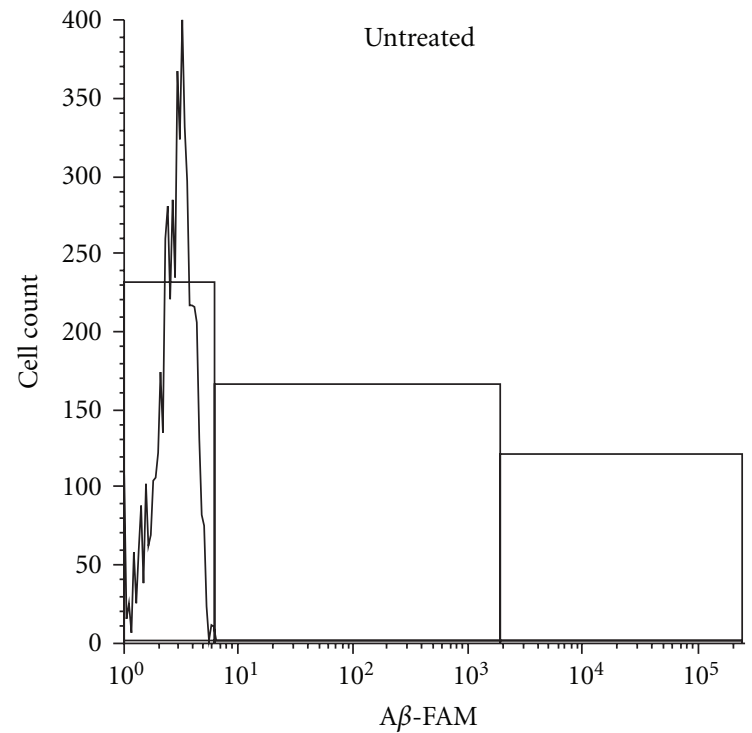

(a)

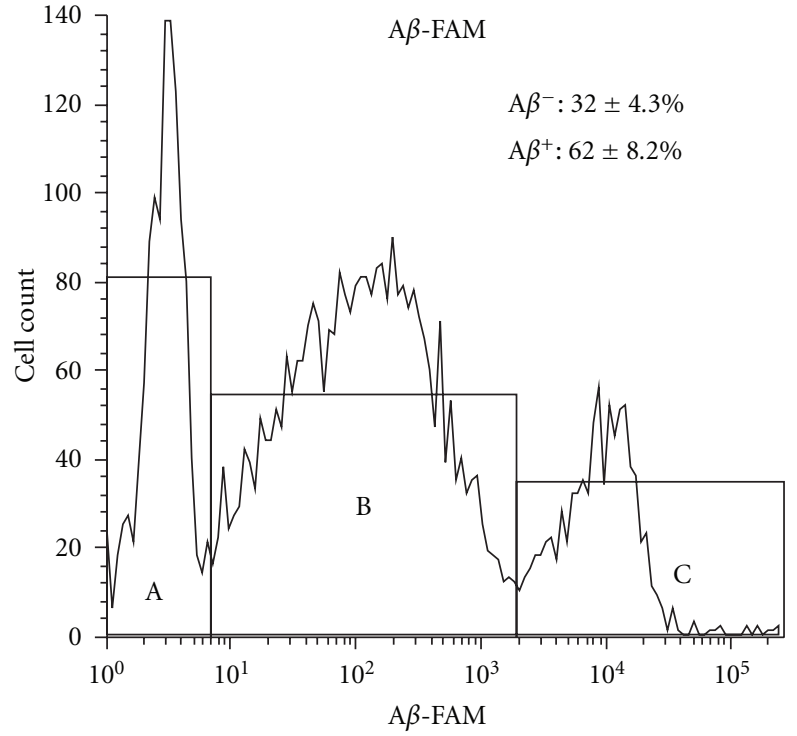

(b)

FIGURE 1: Fluorescence analysis of A $\beta$-FAM binding on PC12 cells. PC12 cells were exposed to A $\beta$-FAM for a short period of time ( 80 min). Based on the levels of intensity of bound $A \beta$-FAM cells are grouped into three distinct subpopulations: a population of cells that did not bind $\mathrm{A} \beta$ (subpopulation $\mathrm{A}$ ), a population of cells that show a high binding affinity for $\mathrm{A} \beta$ (subpopulation $\mathrm{B}$ ), and a population of cells that show an extra high binding affinity for $\mathrm{A} \beta$ (subpopulation $\mathrm{C}$ ). Fluorescence analysis showed that approximately $62 \%$ of all PC12 cells in the culture were classified as $\mathrm{A} \beta$ positive $\left(\mathrm{A} \beta^{+}\right)$.

untreated PC12 cells is high compared to other cell lines, we attempted to artificially increase this percentage in order to make it easier to observe the reducing effect of the PtdSer antibody. In these experiments, the time of exposure to $A \beta$ FAM was extended to six hrs in order to allow A $\beta$-FAM to increase the initial percentage of $\mathrm{PS}^{+}$cells. We have described before that one of the early effects of $A \beta$ in cells is to increase the externalization of PS [2]. Exposure to $A \beta$-FAM for six hrs is longer when compared to the short exposure time, 80 and $120 \mathrm{~min}$, used in the experiments shown in Figures 1 and 2, but still not too long to jeopardize the viability of cells [2]. The $R 2$ gate, annexin V-PE positive cells, in the multigraph Figure 4(b) shows that after cells were exposed to A $\beta$-FAM alone, $80 \%$ of cells were detected by annexin V-PE as $\mathrm{PS}^{+}$. This percentage is considerably higher than the $38 \%$ observed in untreated cells (Figure 4(a)). When cells were first treated with the anti-PS antibody and then with $A \beta$ FAM, the percentage of $\mathrm{PS}^{+}$cells detected by annexin V-PE was noteworthy reduced from $80 \%$ to $59 \%$, indicating a $26 \%$ change. The analysis based on $\mathrm{A} \beta$-FAM binding illustrates that the cell binding of $A \beta$-FAM was also reduced by the treatment with the anti-PS antibody. The $R 1$ gate, $\mathrm{A} \beta$-FAM positive cells, in the multigraph Figure 4(c) shows that after cells were exposed for six hours to A $\beta$-FAM, $96 \%$ of cells were detected as $\mathrm{A} \beta^{+}$cells. However, when cells were treated with the anti-PS antibody before exposed to A $\beta$-FAM, the percentage of $\mathrm{A} \beta^{+}$cells was reduced to $61 \%$. Altogether these results demonstrate that treating cells with anti-PS antibody reduces the level of detectable surface PtdSer and also reduces the number of surface membrane binding sites for $A \beta$-FAM.
3.4. Flow Cytometric Analysis Shows a Correlation between the Binding of $A \beta-F A M$ to the Surface Membrane and the Levels of Cholesterol within the Membrane. Since cholesterol is the most abundant sterol associated with phospholipids in cell membranes, we studied any possible correlation between the levels of membrane cholesterol and $\mathrm{A} \beta$-FAM surface membrane binding. We followed both $\mathrm{A} \beta$-FAM fluorescence and cholesterol indicator Filipin III staining protocols to simultaneously evaluate $\mathrm{A} \beta$-FAM binding and surface membrane cholesterol. The immortalized cell line PC12 cells were incubated first for 80 minutes in PBS containing A $\beta 42$-FAM, washed from unbound $A \beta 42$-FAM, and then incubated for 40 minutes in PBS containing Filipin III. The percentage of cells binding $\mathrm{A} \beta$-FAM and the levels of surface membrane cholesterol were obtained from flow cytometric analysis of the fluorescence from $\mathrm{A} \beta$-FAM and Filipin bound to cells, respectively. Similarly as shown in the histograms described in Figure 1, flow cytometric analysis of the fluorescence from $\mathrm{A} \beta$-FAM distinguished three distinct subpopulations of PC12 cells. The analysis of the cholesterol content of these subpopulations based on Filipin III fluorescence is shown in Figure 5(a). A remarkable correlation was observed between the level of $A \beta$-FAM binding and the level of membrane cholesterol. The highest level of filipin III fluorescence is observed in the cells from the subpopulation defined as extra high A $\beta$-FAM affinity $(C)$. To quantify the results, cells were counted within the $M$ gate which was defined to include a majority of cells with the highest filipin III fluorescence. The table shows the results from the experiment shown in Figure 5(a) in terms of the percentage of cells (\%) and the filipin III Geometric-Mean of Fluorescence (GeoMF) in the 

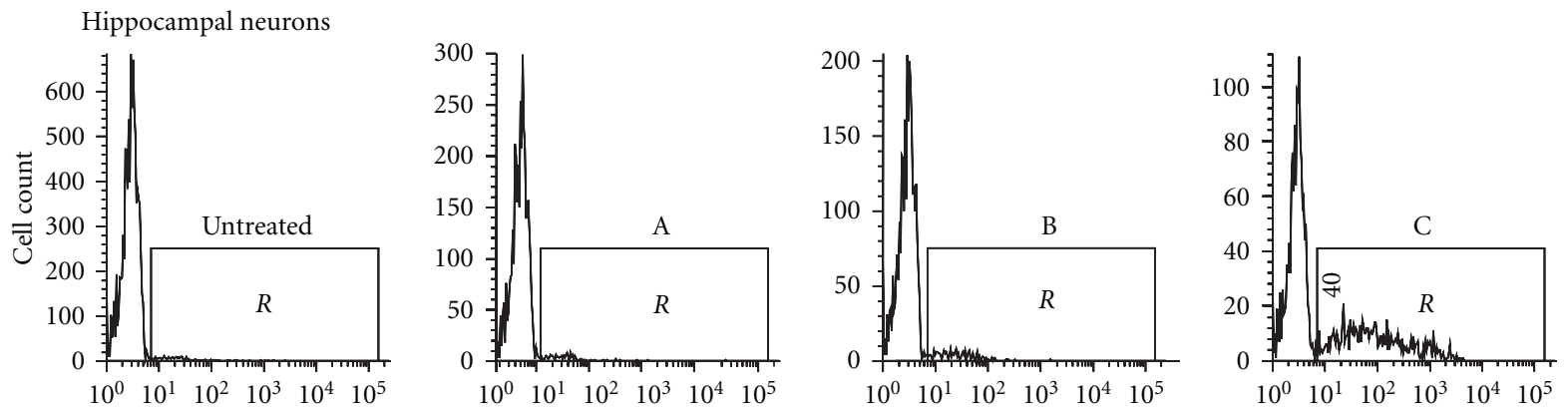

PC12 cells
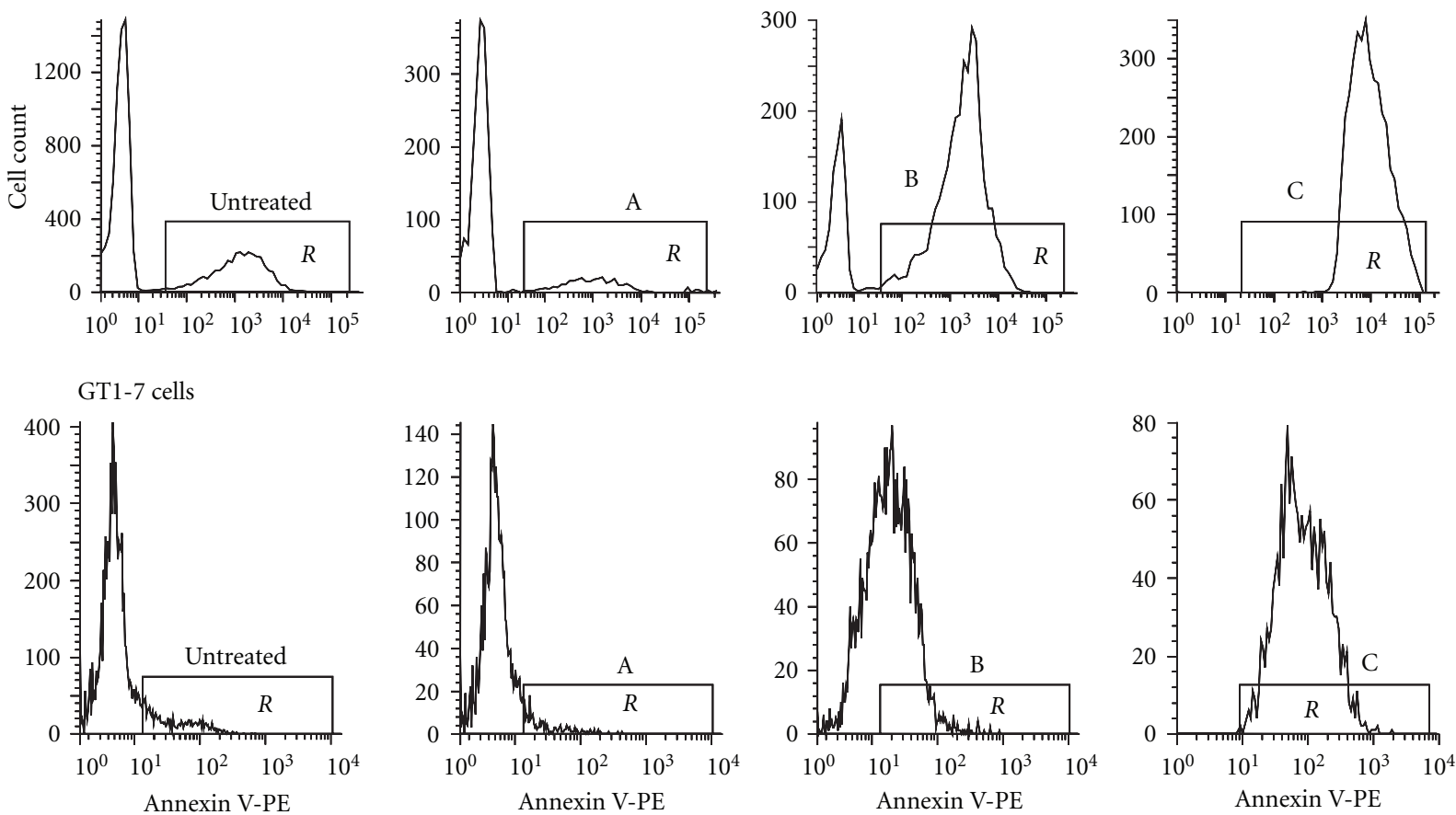

(a)

\begin{tabular}{|c|c|c|c|c|}
\multicolumn{1}{c|}{} & \multicolumn{5}{c|}{ Cell group (\%/GeoMF) } \\
\cline { 2 - 5 } \multicolumn{1}{c|}{} & $\begin{array}{c}\text { Untreated } \\
\text { cells }\end{array}$ & A & B & C \\
\hline Hippocampal neurons & $3 / 25$ & $3 / 22$ & $7 / 26$ & $37 / 93$ \\
\hline PC12 cells & $33 / 751$ & $17 / 696$ & $79 / 1082$ & $100 / 10481$ \\
\hline GT1-7 cells & $14 / 16$ & $7 / 16$ & $65 / 22$ & $100 / 129$ \\
\hline
\end{tabular}

(b)

Figure 2: Correlation between A $\beta$-FAM binding and the levels of surface phosphatidylserine in different types of cells. Hippocampal neurons, PC12, and GT1-7 cells were double fluorescence labeled with A $\beta$-FAM and annexin V-PE. The histograms show fluorescence analysis from the three types of cells based on levels of intensity of the cell-bound annexin V-PE of each one of the subpopulations as defined in Figure 1. There is a remarkable correlation between the level of A $\beta$-FAM binding and the level of PtdSer. The table below shows representative results in terms of the percentage of cells (\%) and the annexin V-PE Geometric-Mean of Fluorescence (GeoMF) in the gate $R$.

gate $M$. The extra high A $\beta 42-F A M$ affinity subpopulations of cells showed 4 times higher GMF values as compared to cells with no A $\beta 42-$ FAM affinity. The bars plot in Figure 5(b) summarizes the percentage of cells and the GMF values within gate $M$ corresponding to each subpopulation. The data in this figure are the pooled results obtained from four experiments. The data compellingly show a correlation between the levels of cholesterol in the membrane and the binding of $A \beta$-FAM to the surface.

3.5. Fluorescence-Activated Cell Sorting Based on A $\beta-F A M$ Fluorescence Confirms the Correlation of the Levels of $A \beta$ Binding to the Membrane Surface with the Levels of Cholesterol within the Membrane. The correlation between A $\beta$-FAM binding and the levels of membrane cholesterol observed 

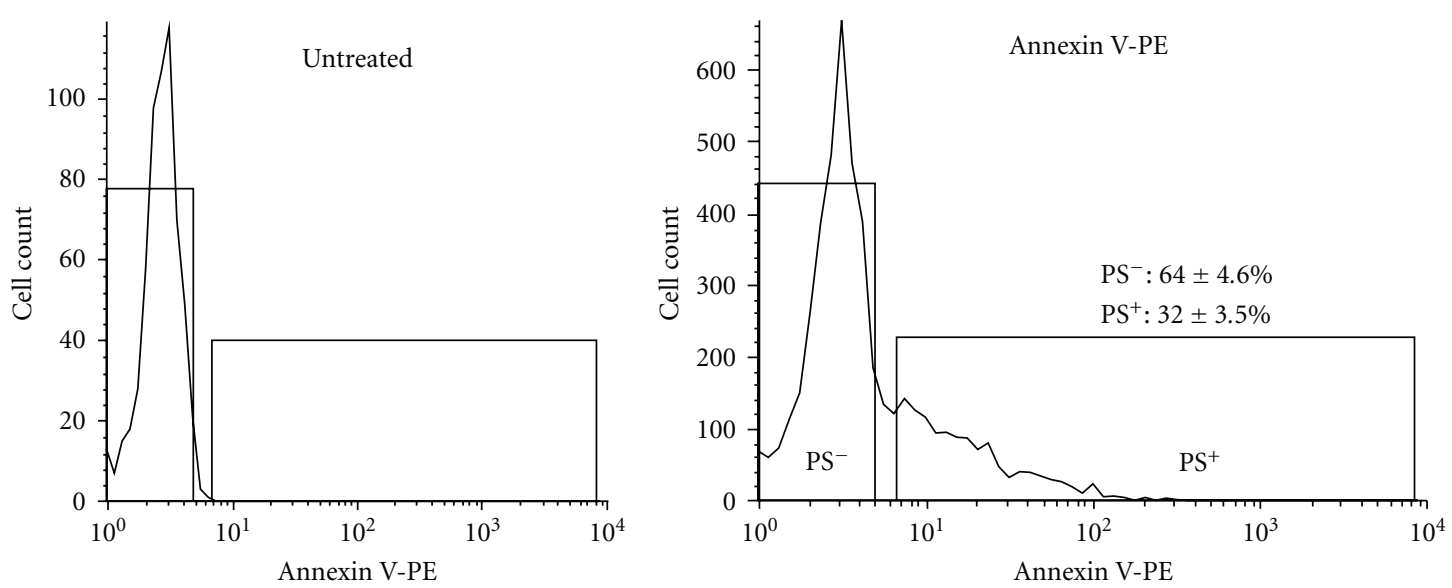

(a)

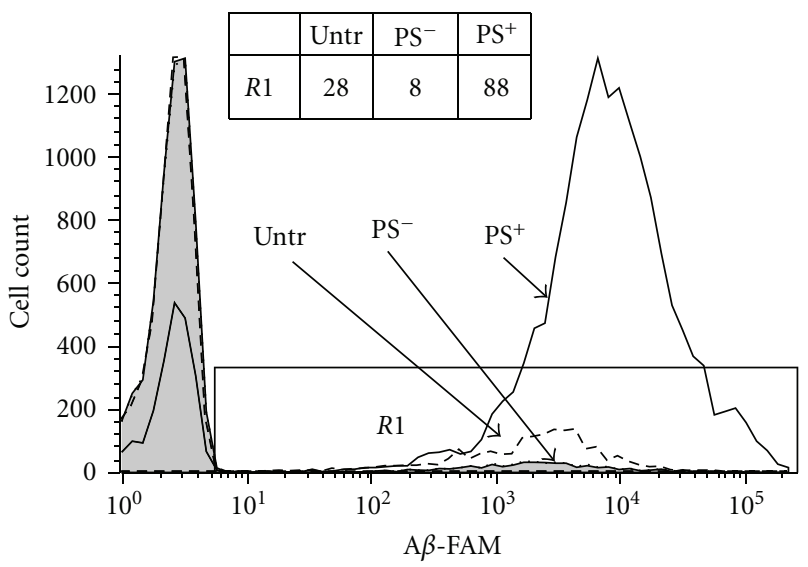

(b)

Figure 3: Correlation between A $\beta$-FAM binding and surface PtdSer observed on cells sorted on the basis of annexin V-PE binding. PC12 cells were exposed to annexin V-PE for $20 \mathrm{~min}$, and sorted based on the levels of annexin V-PE binding. The histograms in (a) show the results of the distribution of the cells. The numbers in the figures are the averaged percentage of PtdSer ${ }^{-}$and $\mathrm{PtdSer}^{+}$cells from four sorting experiments. The resulting groups of cells, untreated control, $\mathrm{PtdSer}^{+}$, and $\mathrm{PtdSer}^{-}$were then treated with A $\beta$-FAM. (b) shows the fluorescence histograms on the basis of $\mathrm{A} \beta$-FAM binding. The results of cell count in the $R 1$ gate, $\mathrm{A} \beta$-FAM positive cells, show that the $\mathrm{PtdSer}^{+}$group of cells has the highest percentage $(88 \%)$ of cells with bound $\mathrm{A} \beta$.

in the flow cytometric analysis of $\mathrm{A} \beta$-FAM and Filipin bound to cells shown in Figure 5 was also observed in fluorescence-activated cell sorting experiments. PC12 cell and hippocampal neuronal cells were exposed for 80 minutes to $A \beta$-FAM for binding and then sorted on the basis of the FAM fluorescence. Sorted cells were cultured and allowed to grow for eight days. Membrane cholesterol levels were measured at 1 and at 8 days after sorting. The bar plots in Figures 6(a) and 6(b) show the results for the PC12 cell and hippocampal neuronal cells, respectively. Cells sorted for their high $\mathrm{A} \beta$-FAM affinity have a higher membrane cholesterol level compared to cells with no affinity for $\mathrm{A} \beta$ FAM. The correlation between A $\beta$-FAM binding and the membrane cholesterol level, measured right after cells were exposed to A $\beta$-FAM (Figure 5), is also observed 1 and 8 days after cell sorting. Our experiments in these two types of cells show that eight days after cell sorting, the differential cholesterol level and the differential level of A $\beta$-FAM binding [3] in the two subpopulation are also sustained.
3.6. A Linear Correlation between A $\beta-F A M$ Binding to the Surface Membrane and the Levels of Cholesterol within the Membrane Persists over a Wide Range of Membrane Cholesterol. The correlation between A $\beta$-FAM binding to the surface of the membrane and the levels of cholesterol in the membrane was tested over a wide range of membrane cholesterol. The content of cholesterol in the membrane was artificially changed following previously used experimental procedures. To decrease the level of membrane cholesterol, cells were exposed to methyl- $\beta$-cyclodextrin $(\mathrm{CD})$ and to the HMG-CoA reductase inhibitor mevastatin. These two procedures have been successfully used to reduce cholesterol from the surface membrane of cultured cells [21-25]. CD efficiently extracts cholesterol from the surface membrane of cultured cells, and mevastatin inhibits the de novo synthesis of cholesterol consequently reducing the content of cholesterol in the plasma membrane. The combined inhibition of HMG-CoA reductase, followed by moderate cell exposure to $\mathrm{CD}$, has also been found to produce a 

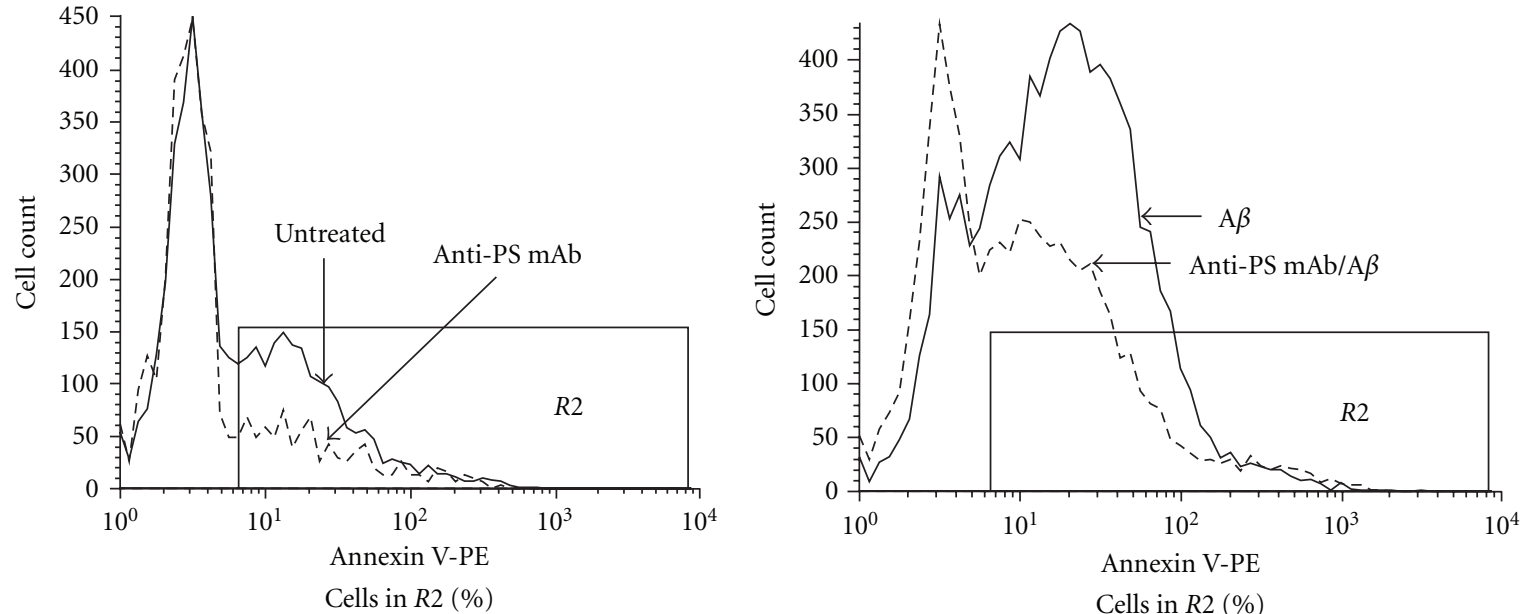

\begin{tabular}{|c|c|c|}
\hline Anti-PS mAb & Untr & $\Delta \%$ \\
\hline 22 & 38 & 42 \\
\hline
\end{tabular}

\begin{tabular}{|c|c|c|}
\hline Anti-PS mAb/A $\beta$ & $\mathrm{A} \beta$ & $\Delta \%$ \\
\hline 59 & 80 & 26 \\
\hline
\end{tabular}

(a)

(b)

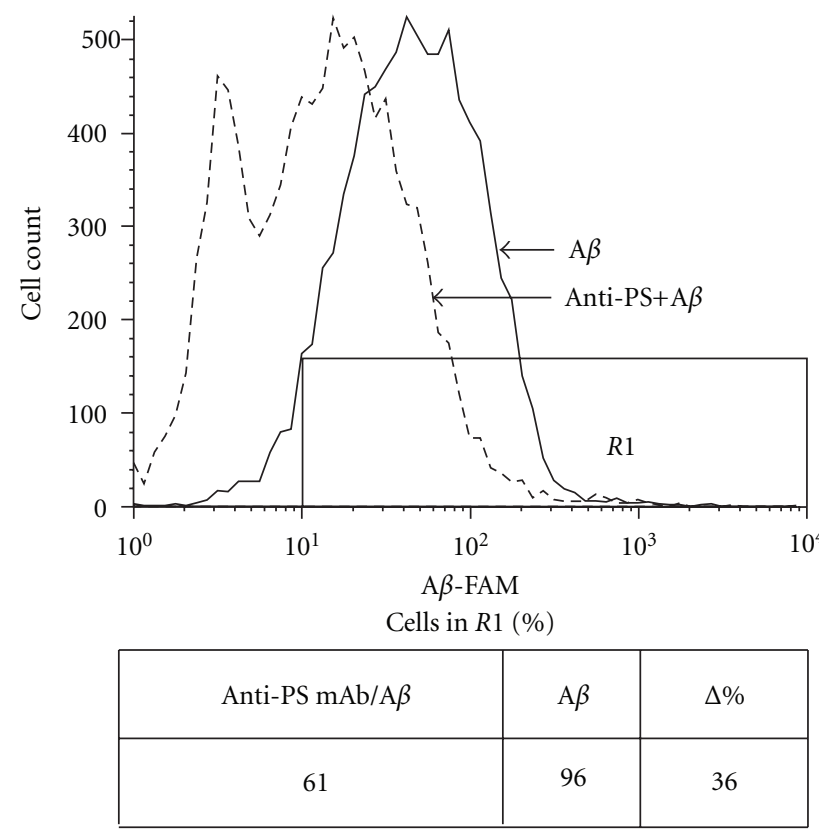

(c)

FIgURE 4: Specific antibody to PtdSer reduces the number of surface membrane binding sites for A $\beta$-FAM. PC12 cells were exposed for 20 min to annexin V-PE, for PtdSer identification, and for $6 \mathrm{hrs}$ to A $\beta$-FAM to study A $\beta$-FAM binding before and after treatment with anti-PtdSer monoclonal antibody (Anti PtdSer mAb). The fluorescence histograms in (a) show that cells treated with anti-PtdSer mAb reduced the percentage of $\mathrm{PtdSer}^{+}$cells in gate $R 2$ by $42 \%$ of the untreated value. The fluorescence histograms in (b) show that the combined treatment of anti-PtdSer mAb and A $\beta$-FAM reduced the percentage of $\mathrm{PtdSer}^{+}$cells in gate $R 2$ by $26 \%$ of the value observed after treatment with $\mathrm{A} \beta$-FAM alone. The fluorescence histograms in (c) show that $\mathrm{A} \beta$-FAM binding, measured as $\mathrm{A} \beta^{+}$cells in $R 1$, is also reduced, by $36 \%$, when cells are pretreated with anti-PtdSer mAb. The tables in each panel show the percentage of PtdSer ${ }^{+}$and A $\beta^{+}$cells in gates $R 2$ and $R 1$, respectively and $\Delta \%$ represents the percentage of the change.

significant reduction in cellular membrane cholesterol on PC12 cells [26]. Hence, to reduce the levels of cholesterol in the surface membrane, PC12 cells were exposed to media containing (CD), mevastatin, or a combination of both. To increase the cholesterol content of the surface membrane, cells were incubated in media enriched with soluble cholesterol which is directly taken up by the cell membrane [26].

The histograms shown in Figure 7(a) show the distribution of cells based on the A $\beta$-FAM fluorescence 

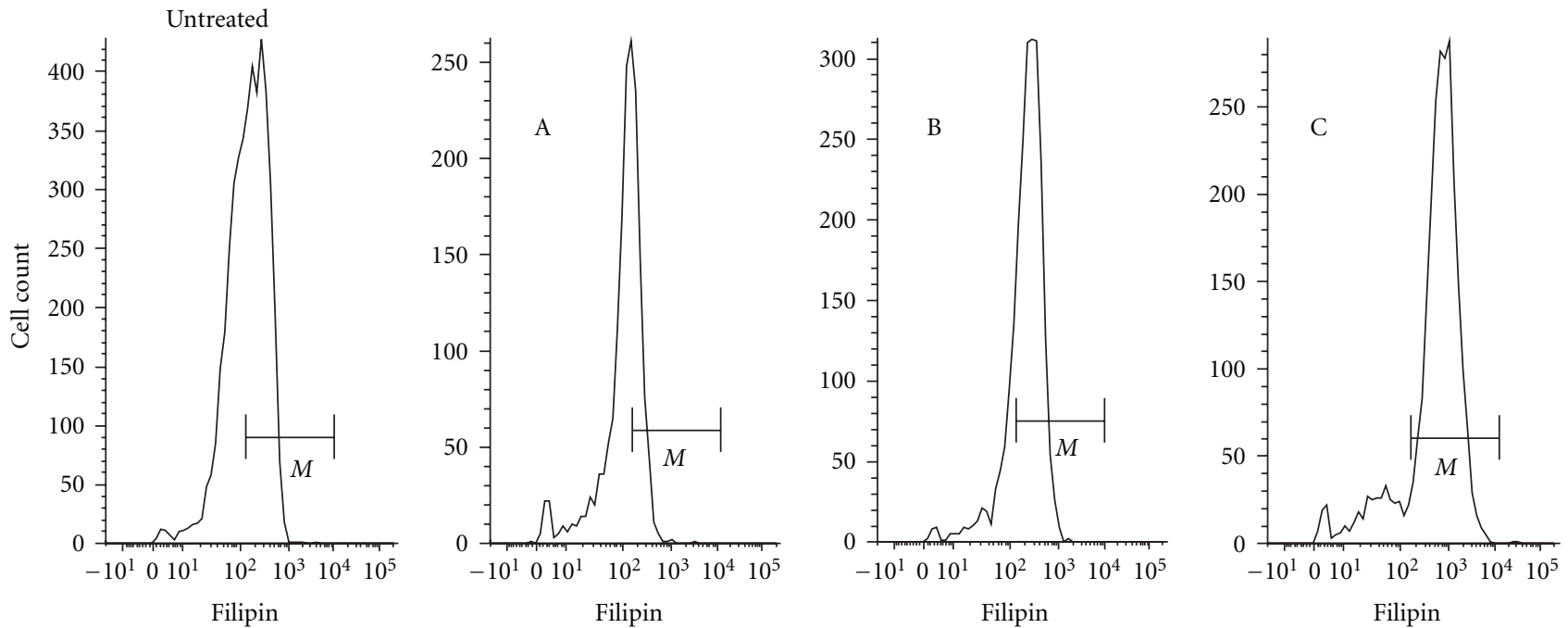

\begin{tabular}{|c|c|c|c|c|}
\cline { 2 - 5 } \multicolumn{1}{c|}{} & \multicolumn{4}{c|}{ Cell group (\%/GeoMF) } \\
\cline { 2 - 5 } \multicolumn{1}{c|}{} & $\begin{array}{c}\text { Untreated } \\
\text { cells }\end{array}$ & A & B & C \\
\hline PC12 cells & $56 / 303$ & $44 / 217$ & $77 / 316$ & $86 / 870$ \\
\hline
\end{tabular}

(a)

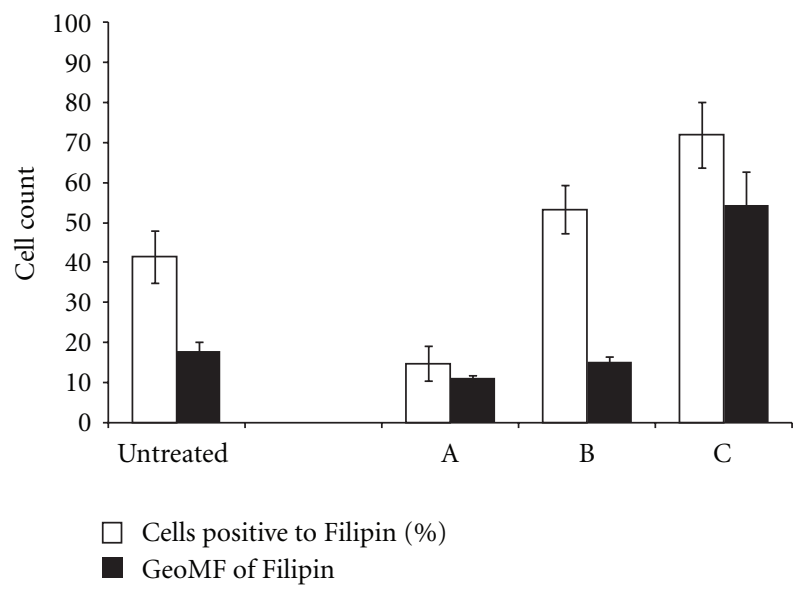

(b)

FIGURE 5: Correlation between the levels of cholesterol in the membrane and the binding of A $\beta$-FAM to the membrane surface. PC12 cells were exposed for 80 minutes to A $\beta 42$-FAM, washed to remove unbound $A \beta$-FAM, and then incubated for 40 minutes in PBS containing Filipin III. (a) shows the flow cytometric analysis of the cholesterol content of the three subpopulations of cells distinguished on the bases of the level of A $\beta$-FAM binding. The percentage of cells and the Geo mean of fluorescence (GeoMF) values measured within the $M$ gate are displayed in the bottom table. The highest level of filipin III fluorescence is observed in the cells from the subpopulation C, defined as extra high A $\beta$-FAM affinity. The bars plot in (b) summarizes the percentage of cells and the GMF values within gate $M$ corresponding to each subpopulation of data pooled from four experiments.

from PC12 cells treated with different concentrations of CD. PC12 cells were exposed for 40 minutes to media containing CD. Then, cells were exposed for 80 minutes to $\mathrm{CD}$-free $\mathrm{A} \beta$-FAM-containing medium. The fluorescence from the membrane bound $\mathrm{A} \beta$-FAM was evaluated by flow cytometry. As the extraction of cholesterol is increased by exposing cells to media with increasing concentrations of $\mathrm{CD}, 1-16 \mathrm{mM}$, the percentage of $\mathrm{A} \beta^{+}$cells was gradually reduced from $82 \%$ in normal medium to $42 \%$ after treated with $16 \mathrm{mM}$ of CD. The histograms in Figure 7(b) show the distribution of the cells based on the A $\beta$-FAM fluorescence from PC12 cells treated with mevastatin and mevastatin plus CD. PC12 cells were cultured in the presence of $5 \mu \mathrm{M}$ mevastatin for 24 hours and then exposed for 80 minutes to either mevastatin-free $\mathrm{A} \beta$-FAM-containing medium or mevastatin- $\mathrm{A} \beta$-FAM-containing medium. In one condition, $4 \mathrm{mM} \mathrm{CD}$ was added for 40 minutes to the mevastatin-containing media before the media was 


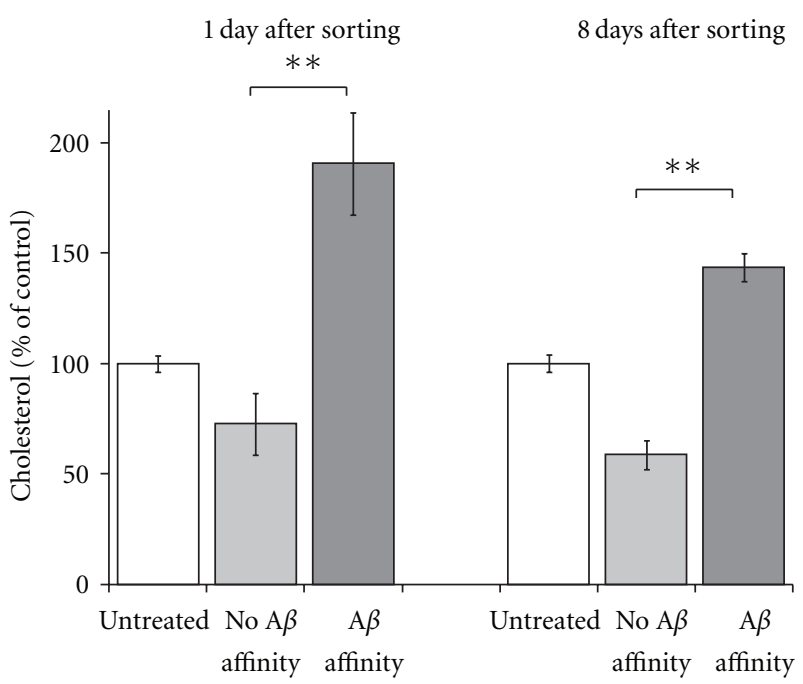

(a)

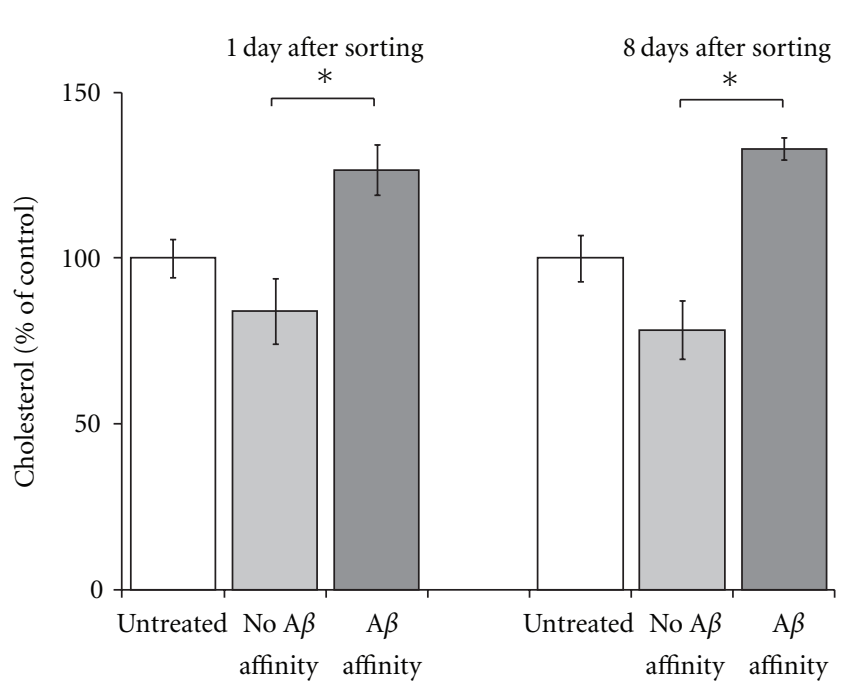

(b)

FIGURE 6: Correlation between A $\beta$-FAM binding and the levels of membrane cholesterol observed in cells sorted on the basis of the A $\beta$-FAM fluorescence. PC12 cell and hippocampal neuronal cells were exposed for 80 minutes to A $\beta$-FAM for binding and then sorted on the basis of the FAM fluorescence. After sorting A $\beta$-FAM, treated cells were pooled into two populations: no A $\beta$-FAM affinity and A $\beta$-FAM affinity. Cells were cultured and allowed to grow and membrane cholesterol levels were measured at 1 and at 8 days after sorting. (a) and (b) show the results for the PC12 cell and hippocampal neuronal cells, respectively. The correlation between the levels of A $\beta$-FAM binding and the levels of membrane cholesterol is observed even after 8 days of cell sorting.

replaced by mevastatin-A $\beta$-FAM-containing medium. When cells were cultured in the presence of mevastatin, mevalonate $(500 \mu \mathrm{M})$ was simultaneously added to the culture medium to prevent cell growth inhibition. The histograms show that the percentage of $\mathrm{A} \beta^{+}$cells was reduced from $59 \%$ in untreated conditions to 42 and $27 \%$ when treated with mevastatin. The combination of procedures was more efficient than the application of the each procedure separately. The percentage of $\mathrm{A} \beta^{+}$cells within gate $R$ was further reduced to $17 \%$. The histograms in Figure 7(c) show the distribution of the cells based on the $A \beta$-FAM fluorescence from cells incubated in media enriched with soluble cholesterol. PC12 cells were incubated with water-soluble $0.52 \mathrm{mM}$ cholesterol (polyoxyethanylcholesteryl sebacate) for 2 hours. Then, cells were exposed for 80 minutes to $A \beta$-FAM-containing medium, and the fluorescence from the membrane bound $A \beta-F A M$ was evaluated by flow cytometry. The histograms show that enriching the cell surface membrane with cholesterol, the percentage of $\mathrm{A} \beta^{+}$cells increases from $50 \%$, cells incubated in normal medium, to $68 \%$ when cells are incubated in cholesterol-enriched medium.

To examine the correlation linking $\mathrm{A} \beta$-FAM binding to the surface membrane with membrane cholesterol over an extended range of cholesterol levels in the membrane, the values from flow cytometric analysis of the fluorescence from Filipin, recorded at the time when membrane-bound $\mathrm{A} \beta$-FAM was measured, are plotted in Figure $7(\mathrm{~d})$. The plot compiles the percentages, relative to control, of $\mathrm{A} \beta^{+}$cells and cholesterol membrane levels which were obtained from the application of the different experimental procedures altering the levels of cholesterol in the surface membrane. Linear regression analysis to the data reveals that within the resulting range of cholesterol levels there is a rather good linear relationship $(R=0.93977)$ between membrane cholesterol levels and $\mathrm{A} \beta$ membrane binding.

\section{Discussion}

In previous investigations, we showed that a firm binding of $A \beta$ to the cell membrane is first required for $A \beta$ to initiate a toxic effect $[2,3]$. We showed that $A \beta$ is also specifically selective in binding just to define subpopulations of the cells in culture [3]. A sensible rationale based on these two pieces of information is to attribute the $A \beta$ cell selectivity to the characteristic binding properties of cells. Consequently, surface membrane signal molecules are going to play an important part in assisting $A \beta$ to achieve one of its most notorious fateful roles. Here we performed fluorescent analyses of the binding of A $\beta$-FAM to the surface membrane of different types of cells lines such as PC12, GT1-7, and ex vivo neurons and studied the influence of the natural membrane component PS and cholesterol on that cell-selective binding. Flow cytometric analyses were made on unsorted cells and on populations of cells that were previously sorted on the basis of their level of bound fluorescent $\mathrm{A} \beta$-FAM or fluorescent annexin V. We artificially modified the levels of the natural membrane components PS and Cholesterol to study the influence of these components on the magnitude of the binding of $A \beta$-FAM to the cell surface membrane. The data presented here revealed that, within a wide range of cholesterol and PS levels, the 


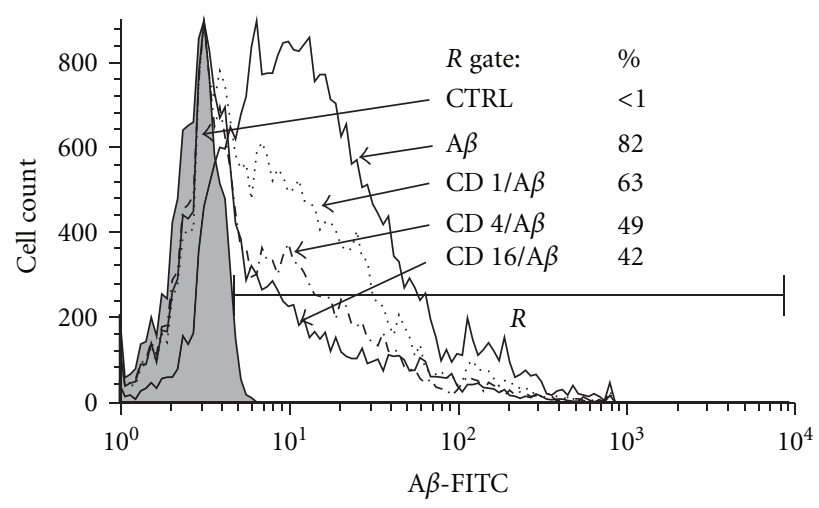

(a)

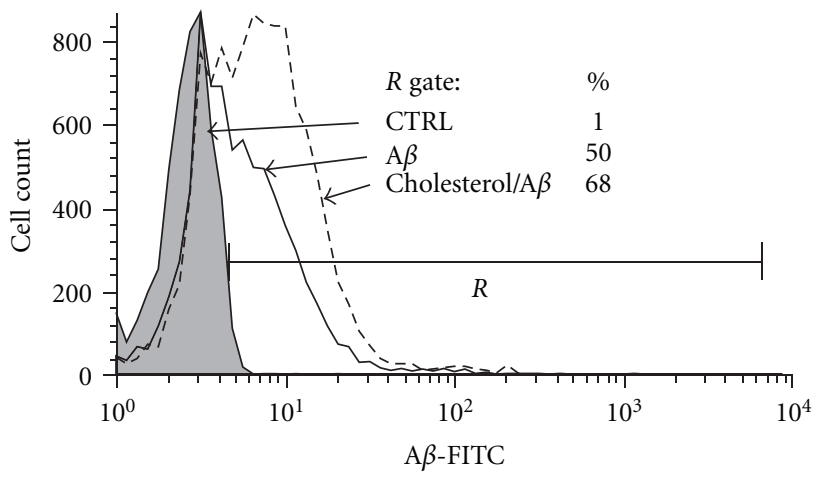

(c)

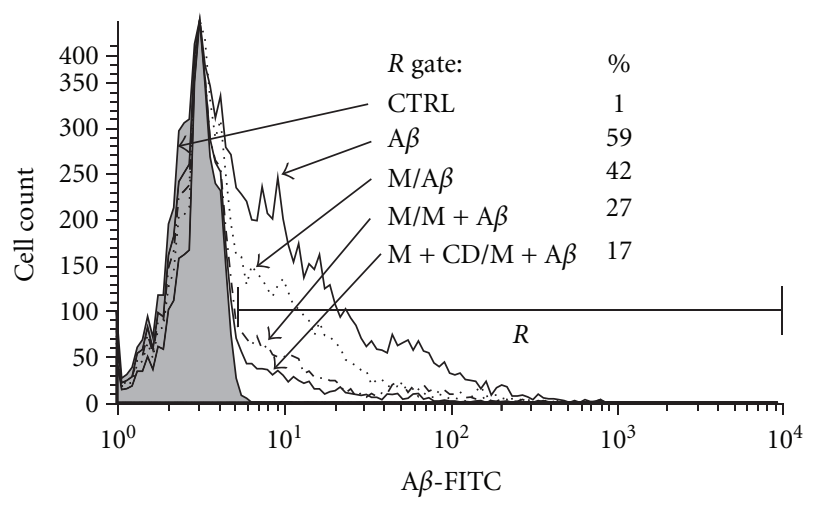

(b)

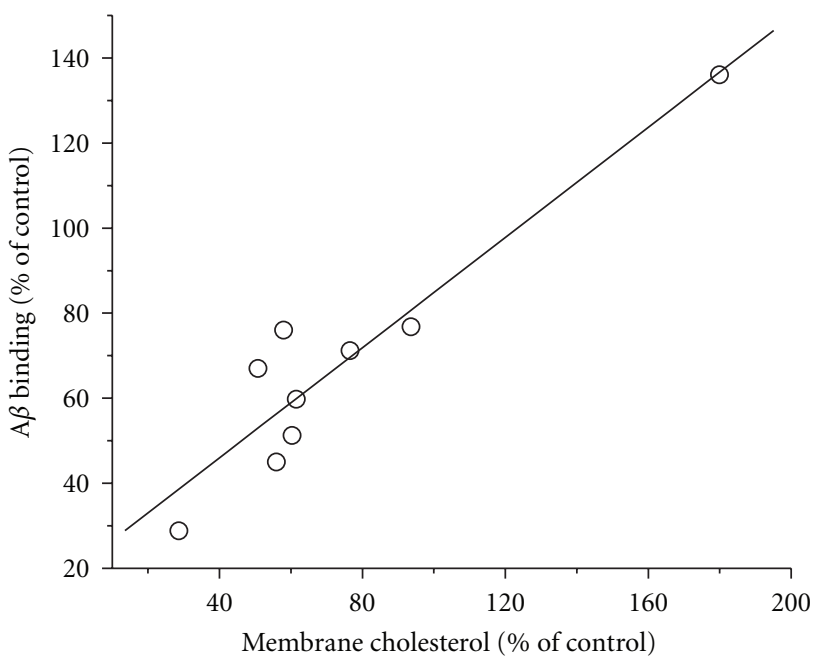

(d)

FIGURE 7: Correlation between A $\beta$-FAM binding and the levels of cholesterol in the membrane over a wide range of membrane cholesterol. To vary the levels of cholesterol in the cell membrane, PC12 cells were treated with different concentrations of methyl- $\beta$-cyclodextrin (CD) (a), mevastatin $(M),(b)$ and polyoxyethanyl-cholesteryl sebacate (Cholesterol) (c). Then, cells were exposed for 80 minutes to A $\beta$-FAM and the fluorescence from the membrane bound $\mathrm{A} \beta$-FAM was evaluated by flow cytometry. The percentage of cells in gate $R$ (numbers in the figures) shows that enriching or depleting the cell membrane of cholesterol increases or reduces the levels of A $\beta$-FAM binding to the surface of the membrane. The plot in (d) compiles the percentage of $\mathrm{A} \beta^{+}$cells as a function of the level of cholesterol in the membrane recorded at the time when membrane-bound A $\beta$-FAM was measured. The straight line is the result of a linear relation fit of data $(R=0.93977)$.

membrane content of these components shows a striking direct linear correlation with the capacity of the surface membrane to bind $\mathrm{A} \beta$-FAM. Because many reports have demonstrated that the $\mathrm{A} \beta$ toxicity on cells increases at low membrane cholesterol and high surface PS levels, the data presented here enforces the concept that binding and toxic cell-damaging interactions of $A \beta$ with the cell membrane are two distinct events, and the extent of either one of these events is modulated by the relative concentrations of the membrane components. The requirements for $A \beta$ molecules to bind to membranes seem to be independent of the structural configuration required to make $A \beta$ a toxic molecule [27]. $A \beta$ peptides possess a strong surface activity that makes them to prefer to stay in an amphiphilic environment such as the membrane surface region. $\mathrm{A} \beta$ may bind to membranes as nontoxic monomers as well as toxic small aggregates. All the experiments described here were initiated after the addition to the media of fresh prepared A $\beta$-FAM. Therefore, cells in our experiments were exposed indiscriminately to monomers and different aggregated $A \beta$ FAM forms, since A $\beta$-FAM starts to aggregate immediately after it is placed in solution and timely adopt different configurations. It was not the objective of this investigation to discern in which way the stage of aggregation of $A \beta$ FAM may affect its binding to cell membranes; however, we are conscious that monomers and oligomers may affect differently the organization of some membrane components such as cholesterol [28].

We have previously observed that $\mathrm{A} \beta$ binding is not always associated with $\mathrm{A} \beta$ toxicity, although we have shown that $\mathrm{A} \beta$ toxicity is essentially preceded by $\mathrm{A} \beta$ binding [2]. Other reports have shown that the lipid membrane is not perturbed until the peptide $A \beta$ penetrates the membrane. Small angle neutron scattering studies showed that when 
this penetration happens the $\mathrm{A} \beta$ peptides intercalate deeply into the lipid bilayer changing the physical properties of the membrane [26]. A $\beta$ can also change the membrane fluidity $[29,30]$, destabilizing the membrane and inducing membrane fusion [31]. We have shown that when appropriate oligomeric structures of $A \beta$ are located within the membrane, it results in selective changes in the membrane ionic conductance allowing destabilizing ionic influxes [18, 32]. Under the experimental conditions executed in this investigation, relatively low concentration and very short period of time of exposure to $A \beta-F A M$, cells remain apparently unaffected up to several days (Figure 5 and [3]); consequently, we think that the results obtained in this work can be interpreted as mainly to reflect the effect of some membrane components on the initial event, that is, the $\mathrm{A} \beta$ binding to the surface membrane.

This investigation corroborates our previous reports that distinctive cell characteristics, some of them residing in the cell surface membrane, favor $A \beta$ binding to selective cultured neuronal subpopulations [3]. Whether cells were exposed for binding to $\mathrm{A} \beta$-FAM or to annexin V-PE, the results of the fluorescent analysis on the different cell types showed that the cell cultures did not consist of homogeneous cell population, but instead consisted of subpopulations of cells characterized by differential levels of a common target for $A \beta$ and for annexin $\mathrm{V}$ binding. Analysis of these binding characteristics reveals a consistent correlation between A $\beta$-FAM binding and annexin V-PE binding, suggesting a common binding target. We also observed that the correlation between these binding properties is not only present when cells were sorted, but also persists for days after both growth and several cell divisions cycles have occurred. We interpret this observation to be conclusive evidence that the specific binding properties are permanent resident characteristic of certain cell subpopulations, thereby providing an explanation for the specific cell sensitivity to $\mathrm{A} \beta$ bindings and the selective toxicity observed in cultured cells. The annexin $\mathrm{V}$ assay is used as a specific and standard, accepted overall for the detection of the externalized acidic phospholipid PtdSer. Therefore, the binding correlation observed in this investigation strongly supports the proposed idea that PtdSer is the common membrane surface binding target for annexin $\mathrm{V}$ and for $\mathrm{A} \beta$-FAM. Using a different experimental approach that evaluates cell viability, we had previously shown that annexin $\mathrm{V}$ protects against $\mathrm{A} \beta$-peptide toxicity, and based on PtdSer liposome aggregation assays we have suggested that the mechanisms by which $\mathrm{A} \beta$ and annexin $\mathrm{V}$ bind the surface of the cell membrane were by competitive binding to a common site in the apoptotic signal molecule PtdSer [33]. The fluorescent analysis performed here shows that when studying $A \beta$ and annexin $V$ binding to cultured cells it is possible to find that $A \beta$-FAM positive neurons can be also annexin $\mathrm{V}$ positive. The information obtained from the experimental approach in this investigation with cells in culture is not sufficient to question the competitive binding to a common site observed in PtdSer liposome aggregation. The simultaneous binding of $\mathrm{A} \beta$-FAM and annexin $\mathrm{V}$ observed in cells could be explained on the basis of unoccupied binding sites still present in the cells after $A \beta$ exposure. This is expected based on a dynamic competition between these two ligands for a common site (viz, PS). We have previously reported a progressive increase in cell fluorescence which increases with the concentration and the time of exposure to fluorescent $\mathrm{A} \beta$ [3]. By contrast, details of the annexin $\mathrm{V}$ binding with phospholipids have not yet been studied with the same level of detail, and no specific binding site has been identified for either head groups or lipid acyl chain. Conceivably, binding sites may be created by specific conformational changes. On the other hand, it is generally accepted that the $\mathrm{A} \beta$-membrane interaction which precedes the insertion in the membrane occurs by a specific electrostatic interaction of $\mathrm{A} \beta$ with acidic phospholipids of negatively charge membranes. Therefore, the results reported here suggest that the negatively charged lipid, PtdSer, is required to establish an effective $\mathrm{A} \beta$-lipid interaction.

Further support for this idea is that acidic phospholipids stabilize $\mathrm{A} \beta$ into an $\alpha$-helical conformation via electrostatic interaction with the negatively charged membrane interface, thus stabilizing $\mathrm{A} \beta$ membrane binding [34]. The striking correlation between the A $\beta$-FAM affinity and the PtdSerspecific annexin $\mathrm{V}$ binding observed in the different types of cells studied in this work therefore strongly supports the hypothesis proposed from artificial liposome aggregation experiments which describes the acidic phospholipid PtdSer as a possible receptor for $\mathrm{A} \beta$ [33].

In addition to PtdSer, other factors or other membrane components are known to additionally facilitate $\mathrm{A} \beta$ binding to membranes $[13,14]$. Numerous reports have suggested other cell membrane components, such as monosialoganglioside GM1 and cholesterol, as facilitators of the functional interaction of $A \beta$ with cell membranes [12, 14-16, 24, 35]. It is proposed that $\mathrm{A} \beta$ selectively recognizes gangliosideclustered, raft-like membrane microdomains in membranes, and binds to and accumulates on the GM1-rich domains in a time- and concentration-dependent manner. Allegedly, this specific binding to ganglioside results in the alteration of A $\beta$ secondary structure, leading to the formation of amyloid fibrils $[15,35]$. The assembly of higher $A \beta$ aggregates to the formation of amyloid fibrils in these microdomains has been subjected to intense studies [12, 13, 35-37] which suggest that lipid molecules in the surface membrane, such as cholesterol and sphingomyelin, are involved in the process $[12,15]$. The fluorescent analysis performed in this investigation reveals the positive impact of the concentration of cholesterol in the membrane on the extent of $A \beta$ binding to the membrane surface region. Experiments with cells containing different membrane cholesterol levels, achieved by artificially enriching or reducing the cholesterol in the membrane, clearly showed that the amount of $A \beta$-FAM bound on the surface of the membrane linearly correlates with the amount of cholesterol within the membrane. Therefore, the assertion that cholesterol mediates $\mathrm{A} \beta$ binding applies within a wide range of cholesterol concentrations and applies also to various cell types. Cholesterol plays a multifaceted role when it is added to cells in culture, thus an explanation for the correlation with the surface membrane binding of $A \beta$ is more intricate. Cholesterol may interact with $\mathrm{A} \beta$ itself and affects $\mathrm{A} \beta$ conformational state, 
it facilitates the clustering of gangliosides that binds $\mathrm{A} \beta$, as well as it alters the physical-chemical properties of neuronal membranes, including membrane fluidity and membrane lipid dynamics. Some reports affirm that cholesterol not only contributes to $\mathrm{A} \beta$ binding to the surface of the membrane, but the ability of $A \beta$ to insert into the membrane is critically controlled by the ratio of cholesterol to phospholipids [16]. Cholesterol tends to adopt energetically favorable domains in membranes, thus cholesterol domain formation may be actively involved in modulating the interaction of $\mathrm{A} \beta$ with lipid bilayers [28]. These diverse of actions of cholesterol therefore have consequences on $\mathrm{A} \beta$ membrane binding as well as $A \beta$ membrane insertion. When in aqueous solution $\mathrm{A} \beta$ adopts a random-coil conformation; but when reacting with cholesterol-containing vesicles $\mathrm{A} \beta$ undergoes conformational changes that facilitates $\mathrm{A} \beta$ binding or insertion into the membrane [16]. When $\mathrm{A} \beta$ displays a significant population of $\beta$-structures, it is basically surface associated, whereas when it is $\alpha$-helix structured it is most likely transmembrane incorporated [34]. Therefore, the cholesterol modulation of the two separate events that result from the cell's exposure to $\mathrm{A} \beta$, that is, binding and insertion into the membrane $[2,19]$, is related to its membrane concentration levels. Because cholesterol affects $\mathrm{A} \beta$ structure, the membrane components organization, and the membrane physical properties, the results from our fluorescent analysis of cells exposed to A $\beta$ FAM suggest that as cholesterol concentration increases the $\mathrm{A} \beta$ membrane binding event is favored and $\mathrm{A} \beta$ insertion event is prevented. This is in accordance with a series of previous reports that point out that there is a strong dependence of $\mathrm{A} \beta$ insertion and the $\mathrm{A} \beta$ channel activity as a function of the cholesterol content of the surface membrane $[31,38-40]$. We, and others, have also shown that insertion that creates toxic membrane perturbations and cell death is favored as membrane cholesterol levels decrease [25, 37].

\section{Acknowledgment}

This work was financially supported by The Alzheimer's Association of America and by USUHS Grant CO70TS.

\section{References}

[1] B. A. Yankner, "Mechanisms of neuronal degeneration in Alzheimer's disease," Neuron, vol. 16, no. 5, pp. 921-932, 1996.

[2] O. Simakova and N. J. Arispe, "Early and late cytotoxic effects of external application of the Alzheimer's $A \beta$ result from the initial formation and function of $A \beta$ ion channels," Biochemistry, vol. 45, no. 18, pp. 5907-5915, 2006.

[3] O. Simakova and N. J. Arispe, "The cell-selective neurotoxicity of the Alzheimer's A $\beta$ peptide is determined by surface phosphatidylserine and cytosolic ATP levels. Membrane binding is required for A $\beta$ toxicity," Journal of Neuroscience, vol. 27, no. 50, pp. 13719-13729, 2007.

[4] V. A. Fadok, D. R. Voelker, P. A. Campbell, J. J. Cohen, D. L. Bratton, and P. M. Henson, "Exposure of phosphatidylserine on the surface of apoptotic lymphocytes triggers specific recognition and removal by macrophages," Journal of Immunology, vol. 148, no. 7, pp. 2207-2216, 1992.
[5] V. A. Fadok, D. L. Bratton, D. M. Rose, A. Pearson, R. A. B. Ezekewitz, and P. M. Henson, "A receptor for phosphatidylserine-specific clearance of apoptotic cells," Nature, vol. 405, no. 6782, pp. 85-90, 2000.

[6] O. C. Martin and R. E. Pagano, "Transbilayer movement of fluorescent analogs of phosphatidylserine and phosphatidylethanolamine at the plasma membrane of cultured cells. Evidence for a protein-mediated and ATP-dependent process(es)," Journal of Biological Chemistry, vol. 262, no. 12, pp. 5890-5898, 1987.

[7] S. J. Martin, C. P. M. Reutelingsperger, A. J. McGahon et al., "Early redistribution of plasma membrane phosphatidylserine is a general feature of apoptosis regardless of the initiating stimulus: inhibition by overexpression of Bcl-2 and Abl," Journal of Experimental Medicine, vol. 182, no. 5, pp. 15451556, 1995.

[8] R. F. A. Zwaal and A. J. Schroit, "Pathophysiologic implications of membrane phospholipid asymmetry in blood cells," Blood, vol. 89, no. 4, pp. 1121-1132, 1997.

[9] R. F. A. Zwaal, P. Comfurius, and E. M. Bevers, "Surface exposure of phosphatidylserine in pathological cells," Cellular and Molecular Life Sciences, vol. 62, no. 9, pp. 971-988, 2005.

[10] N. Arispe, M. Doh, O. Simakova, B. Kurganov, and A. De Maio, "Hsc70 and Hsp70 interact with phosphatidylserine on the surface of PC12 cells resulting in a decrease of viability," FASEB Journal, vol. 18, no. 14, pp. 1636-1645, 2004.

[11] E. Terzi, G. Hölzemann, and J. Seelig, "Interaction of Alzheimer $\beta$-amyloid peptide(1-40) with lipid membranes," Biochemistry, vol. 36, no. 48, pp. 14845-14852, 1997.

[12] A. Kakio, S. I. Nishimoto, K. Yanagisawa, Y. Kozutsumi, and K. Matsuzaki, "Cholesterol-dependent formation of GM1 ganglioside-bound amyloid $\beta$-protein, an endogenous seed for Alzheimer amyloid," Journal of Biological Chemistry, vol. 276, no. 27, pp. 24985-24990, 2001.

[13] K. Matsuzaki, "Physicochemical interactions of amyloid $\beta$ peptide with lipid bilayers," Biochimica et Biophysica Acta, vol. 1768, no. 8, pp. 1935-1942, 2007.

[14] K. Yanagisawa, "Role of gangliosides in Alzheimer's disease," Biochimica et Biophysica Acta, vol. 1768, no. 8, pp. 1943-1951, 2007.

[15] K. Matsuzaki, K. Kato, and K. Yanagisawa, "A $\beta$ polymerization through interaction with membrane gangliosides," Biochimica et Biophysica Acta, vol. 1801, no. 8, pp. 868-877, 2010.

[16] S.-R. Ji, Y. Wu, and S.-F. Sui, "Cholesterol is an important factor affecting the membrane insertion of $\beta$-amyloid peptide (A $\beta 1-40)$, which may potentially inhibit the fibril formation," Journal of Biological Chemistry, vol. 277, no. 8, pp. 6273-6279, 2002.

[17] J. Vargas, J. M. Alarcón, and E. Rojas, “Displacement currents associated with the insertion of Alzheimer disease amyloid $\beta$ peptide into planar bilayer membranes," Biophysical Journal, vol. 79, no. 2, pp. 934-944, 2000.

[18] N. Arispe, J. C. Diaz, and O. Simakova, "A $\beta$ ion channels. Prospects for treating Alzheimer's disease with $\mathrm{A} \beta$ channel blockers," Biochimica et Biophysica Acta, vol. 1768, no. 8, pp. 1952-1965, 2007.

[19] P. T. Wong, J. A. Schauerte, K. C. Wisser et al., "Amyloid$\beta$ membrane binding and permeabilization are distinct processes influenced separated by membrane charge and fluidity," Journal of Molecular Biology, vol. 386, no. 1, pp. 81-96, 2009.

[20] A. W. Norman, R. A. Demel, B. de Kruyff, and L. L. van Deenen, "Studies on the biological properties of polyene 
antibiotics. Evidence for the direct interaction of filipin with cholesterol," Journal of Biological Chemistry, vol. 247, no. 6, pp. 1918-1929, 1972.

[21] M. Simons, P. Keller, B. De Strooper, K. Beyreuther, C. G. Dotti, and K. Simons, "Cholesterol depletion inhibits the generation of $\beta$-amyloid in hippocampal neurons," Proceedings of the National Academy of Sciences of the United States of America, vol. 95, no. 11, pp. 6460-6464, 1998.

[22] J. C. Diaz and N. Arispe, "GM1 and PS enrichment of cell membranes assists $\mathrm{A} \beta$ membrane binding and ion channel formation," Biophysical Journal, vol. 94, no. 2, p. p1025, 2008.

[23] N. Arispe and O. Simakova, "Alzheimer's disease A $\beta$ peptide binding to cell membranes is correlated to membrane surface phosphatidylserine levels," Biophysical Journal, vol. 92, no. 3, p. $612 \mathrm{a}, 2007$.

[24] O. Simakova and N. Arispe, "High membrane cholesterol levels characterize cells identified by their A $\beta$ binding affinity," Biophysical Journal, vol. 94, no. 2, p. p1025, 2008.

[25] N. Arispe and M. Doh, "Plasma membrane cholesterol controls the cytotoxicity of Alzheimer's disease A $\beta \mathrm{P}(1-40)$ and (1-42) peptides," FASEB Journal, vol. 16, no. 12, pp. 15261536, 2002.

[26] T.-L. Lau, E. E. Ambroggio, D. J. Tew et al., "Amyloid- $\beta$ peptide disruption of lipid membranes and the effect of metal ions," Journal of Molecular Biology, vol. 356, no. 3, pp. 759-770, 2006.

[27] K. Yanagisawa, "GM1 ganglioside and the seeding of amyloid in Alzheimer's disease: endogenous seed for Alzheimer amyloid," Neuroscientist, vol. 11, no. 3, pp. 250-260, 2005.

[28] L. Qiu, A. Lewis, J. Como et al., "Cholesterol modulates the interaction of $\beta$-amyloid peptide with lipid bilayers," Biophysical Journal, vol. 96, no. 10, pp. 4299-4307, 2009.

[29] W. E. Muller, S. Koch, A. Eckert, H. Hartmann, and K. Scheuer, " $\beta$-Amyloid peptide decreases membrane fluidity," Brain Research, vol. 674, no. 1, pp. 133-136, 1995.

[30] A. Buchsteiner, T. Hauß, S. Dante, and N. A. Dencher, "Alzheimer's disease amyloid- $\beta$ peptide analogue alters the ps-dynamics of phospholipid membranes," Biochimica et Biophysica Acta, vol. 1798, no. 10, pp. 1969-1976, 2010.

[31] S. Dante, T. Hauß, A. Brandt, and N. A. Dencher, "Membrane fusogenic activity of the Alzheimer's peptide $\mathrm{A} \beta(1-42)$ demonstrated by small-angle neutron scattering," Journal of Molecular Biology, vol. 376, no. 2, pp. 393-404, 2008.

[32] N. Arispe, E. Rojas, and H. B. Pollard, "Alzheimer disease amyloid $\beta$ protein forms calcium channels in bilayer membranes: blockade by tromethamine and aluminum," Proceedings of the National Academy of Sciences of the United States of America, vol. 90, no. 2, pp. 567-571, 1993.

[33] G. Lee, H. B. Pollard, and N. Arispe, "Annexin 5 and apolipoprotein E2 protect against Alzheimer's amyloid- $\beta$ peptide cytotoxicity by competitive inhibition at a common phosphatidylserine interaction site," Peptides, vol. 23, no. 7, pp. 1249-1263, 2002.

[34] M. Bokvist, F. Lindström, A. Watts, and G. Gröbner, "Two types of Alzheimer's $\beta$-amyloid (1-40) peptide membrane interactions: aggregation preventing transmembrane anchoring versus accelerated surface fibril formation," Journal of Molecular Biology, vol. 335, no. 4, pp. 1039-1049, 2004.

[35] L. P. Choo-Smith and W. K. Surewicz, "The interaction between Alzheimer amyloid $\beta(1-40)$ peptide and ganglioside G(M1)-containing membranes," FEBS Letters, vol. 402, no. 23, pp. 95-98, 1997.

[36] T. Ariga, K. Kobayashi, A. Hasegawa, M. Kiso, H. Ishida, and T. Miyatake, "Characterization of high-affinity binding between gangliosides and amyloid $\beta$-protein," Archives of Biochemistry and Biophysics, vol. 388, no. 2, pp. 225-230, 2001.

[37] C. Cecchi, F. Rosati, A. Pensalfini et al., "Seladin-1/DHCR24 protects neuroblastoma cells against $\mathrm{A} \beta$ toxicity by increasing membrane cholesterol content," Journal of Cellular and Molecular Medicine, vol. 12, no. 5B, pp. 1990-2002, 2008.

[38] T. Mirzabekov, M. C. Lin, W. L. Yuan et al., "Channel formation in planar lipid bilayers by a neurotoxic fragment of the beta-amyloid peptide," Biochemical and Biophysical Research Communications, vol. 202, no. 2, pp. 1142-1148, 1994.

[39] M. Kawahara, Y. Kuroda, N. Arispe, and E. Rojas, "Alzheimer's $\beta$-amyloid, human islet amylin, and priori protein fragment evoke intracellular free calcium elevations by a common mechanism in a hypothalamic GnRH neuronal cell line," Journal of Biological Chemistry, vol. 275, no. 19, pp. 1407714083, 2000.

[40] M. Kawahara and Y. Kuroda, "Intracellular calcium changes in neuronal cells induced by Alzheimer's $\beta$-amyloid protein are blocked by estradiol and cholesterol," Cellular and Molecular Neurobiology, vol. 21, no. 1, pp. 1-13, 2001. 


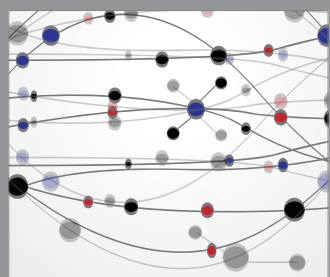

The Scientific World Journal
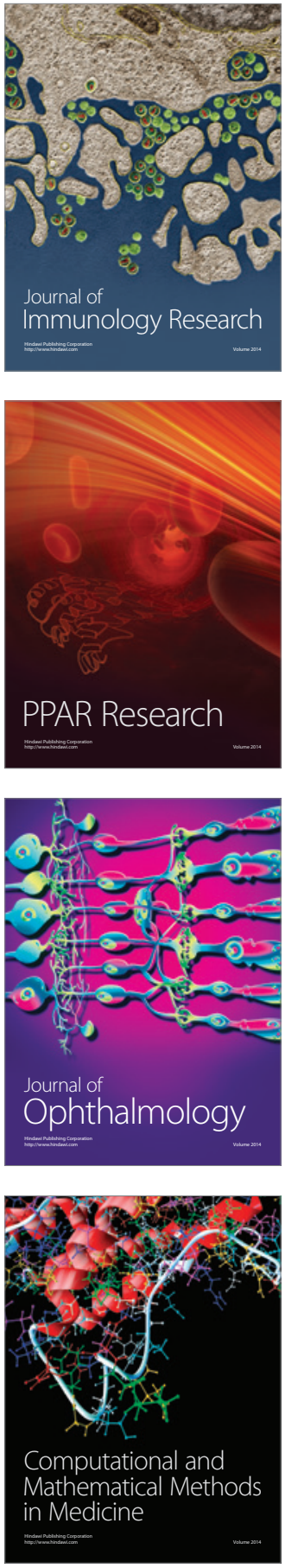

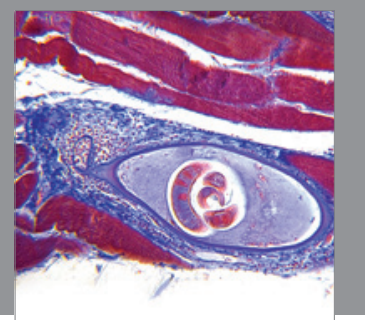

Gastroenterology

Research and Practice
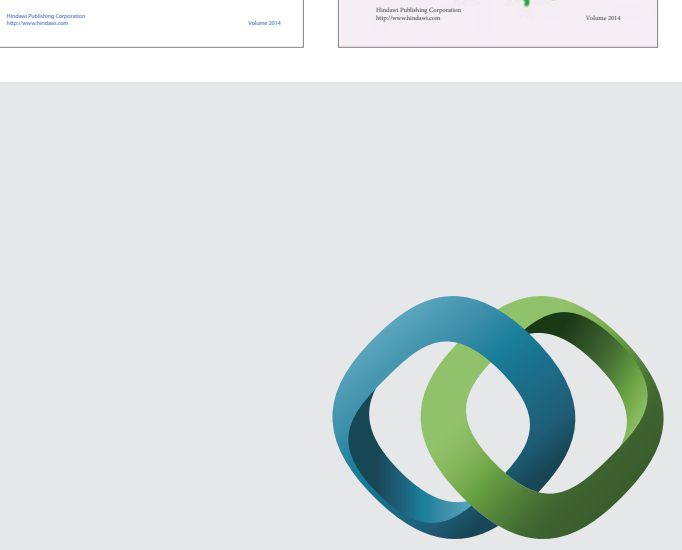

\section{Hindawi}

Submit your manuscripts at

http://www.hindawi.com
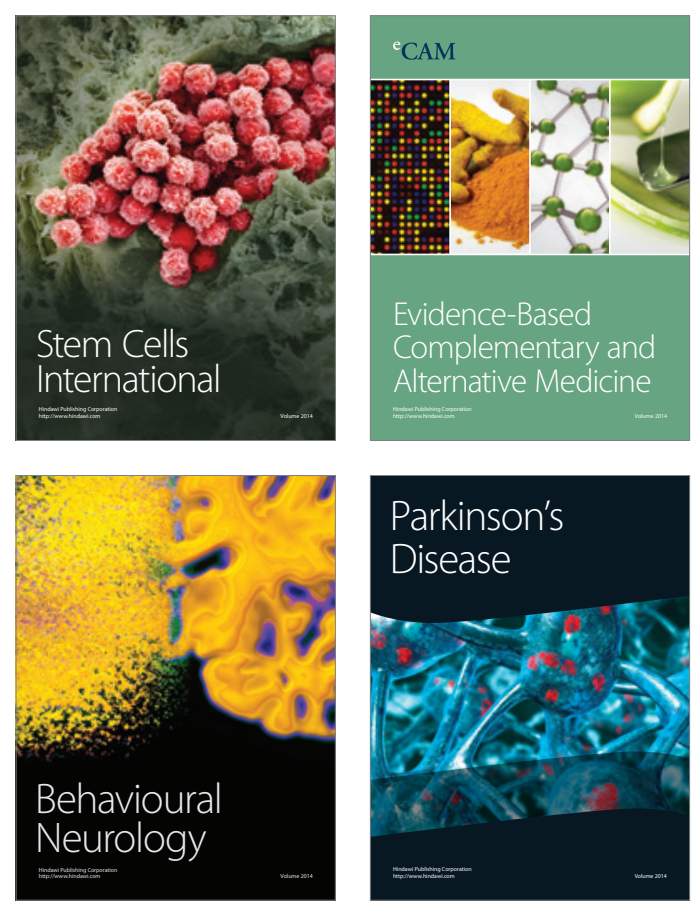

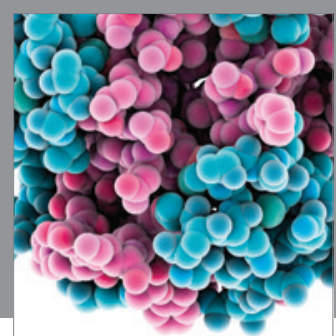

Journal of
Diabetes Research

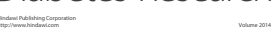

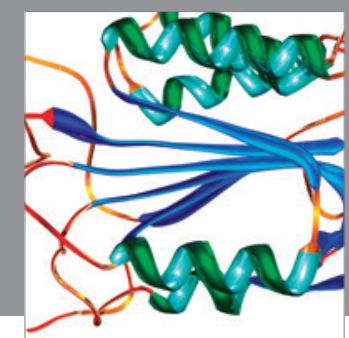

Disease Markers
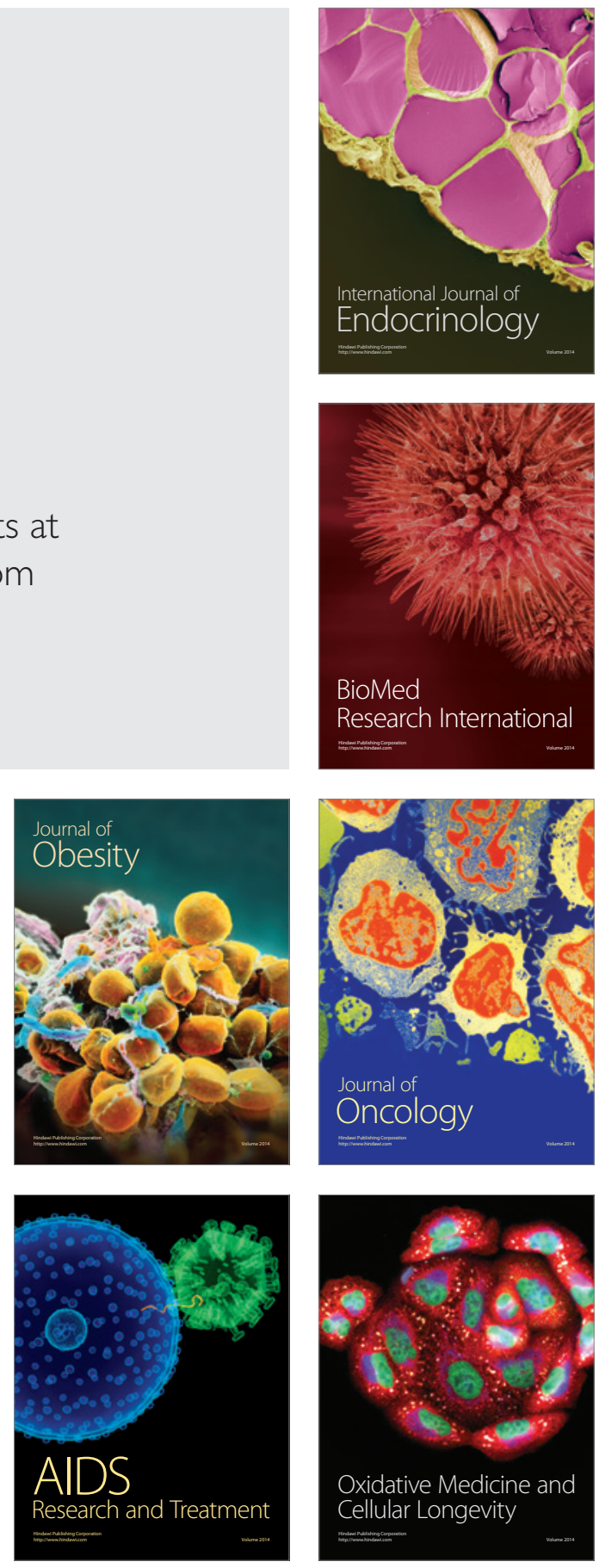